\title{
Diagnostic performance of a new highly sensitive thyroglobulin immunoassay
}

\author{
A lervasi, G Iervasi, A Bottoni, G Boni ${ }^{1}$, C Annicchiarico ${ }^{1}$, \\ P Di Cecco and G C Zucchelli \\ National Council of Research, Institute of Clinical Physiology, Via Moruzzi, 1, 56124 Pisa, Italy \\ ${ }^{1}$ Division of Nuclear Medicine, Department of Oncology, University of Pisa, Pisa, Italy \\ (Requests for offprints should be addressed to G lervasi; Email: iervasi@ifc.cnr.it)
}

\begin{abstract}
The determination of serum thyroglobulin $(\mathrm{Tg})$ is commonly used for detecting the presence of residual thyroid tissue or cancer recurrence in patients treated for differentiated thyroid cancer (DTC). The aim of the study was to evaluate the performance characteristics of a recently introduced fully automated chemiluminescent immunoassay, based on four monoclonal antibodies and which produces results in $40 \mathrm{~min}$. Analytical sensitivity $(0 \cdot 01 \mu \mathrm{g} / \mathrm{l})$ was computed from 20 replicates of the zero calibrator and of the 'Tg-free' sample pool. Functional sensitivity $(0 \cdot 1 \mu \mathrm{g} / 1$ at 20 coefficients of variation percent) was determined from the imprecision profile obtained by assaying ten serum pools. The reliability of the measurements in the low concentration range $(\mathrm{Tg}<1 \mu \mathrm{g} / \mathrm{l})$ has been checked by progressive dilution with the 'Tg-free' serum of a sample
\end{abstract}

pool at $5.27 \mu \mathrm{g} / 1$; measured values were very close to the expected values (recovery 100-133\%).

Cut-off at the 99th percentile in DTC stage I 'diseasefree' treated patients $(n=53)$ was $0 \cdot 16 \mu \mathrm{g} / \mathrm{l}$. Tg measurement in basal conditions during L-thyroxine suppression therapy and 5 days after recombinant human TSH stimulation was performed in 22 patients with DTC. In $80 \%$ of patients with basal $\mathrm{Tg}<0 \cdot 1 \mu \mathrm{g} / 1 \quad(12 / 15), \mathrm{Tg}$ remained $<0 \cdot 1 \mu \mathrm{g} / 1$ after stimulation, and in all of these $\mathrm{Tg}$ was $<1 \mu \mathrm{g} / \mathrm{l}$.

Our results have indicated the optimal analytical and clinical performance of this Tg immunoassay and encourage further studies on larger populations of patients with DTC.

Journal of Endocrinology (2004) 182, 287-294

\section{Introduction}

Thyroglobulin (Tg) is a large glycoprotein (molecular weight $=660000)$ stored in the follicular colloid of the thyroid gland. It acts as a prohormone in the intra-thyroid synthesis of thyroxine (T4) and triiodothyronine (T3) and it is produced only by normal thyrocytes or welldifferentiated thyroid cancer cells. Since the thyroid is the only source of $\mathrm{Tg}$, a rise in $\mathrm{Tg}$ levels in patients after total thyroidectomy and radioiodine ablation of residual thyroid tissue indicates the recurrence of differentiated thyroid cancer (DTC). In this context, a strong correlation between serum $\mathrm{Tg}$ levels and the amount of differentiated thyroid tissue has been reported (Ozata et al. 1994, Duren et al. 1999, Pacini \& Pinchera 1999, Girelli \& De Vido 2000). It is recognized worldwide that the measurement of circulating $\mathrm{Tg}$ represents a fundamental tool in the management and follow-up of patients affected by DTC (Schlumberger 1998, Mazzaferri 1999). In addition, in a very recent $\mathrm{Tg}$ consensus conference (Mazzaferri et al. 2003), a surveillance guideline has been extended to the use of thyrotrophin (TSH)-stimulated Tg levels for thyroidectomized patients without clinical evidence of residual tumour with $\mathrm{Tg}$ values below $1 \mu \mathrm{g} / 1$ during TSH suppression. The detection limit of the methods is critical to detect small amounts of $\mathrm{Tg}$ and to observe a change in $\mathrm{Tg}$ concentration. It has been proposed that only methods providing the greatest distinction between the lower limit of the euthyroid reference range and the functional sensitivity limit of the assay offer the best clinical sensitivity for detecting small amounts of thyroid tissue in the TSH-suppressed state (Spencer et al. 1996). On the other hand, it is noteworthy that, despite the substantial clinical use of $\mathrm{Tg}$ measurement, wide differences still remain between results produced in different laboratories because of poor standardization, the heterogeneity of circulating $\mathrm{Tg}$, interference from anti- $\mathrm{Tg}$ autoantibodies $(\mathrm{AbTg})$, differences in the epitope recognition by the different antibodies used in the different assays (Zucchelli et al. 1996) and interference from heterophile antibodies.

For these reasons, highly sensitive, precise and accurate $\mathrm{Tg}$ assays are needed in the follow-up of patients with DTC even if this goal is technically challenging 

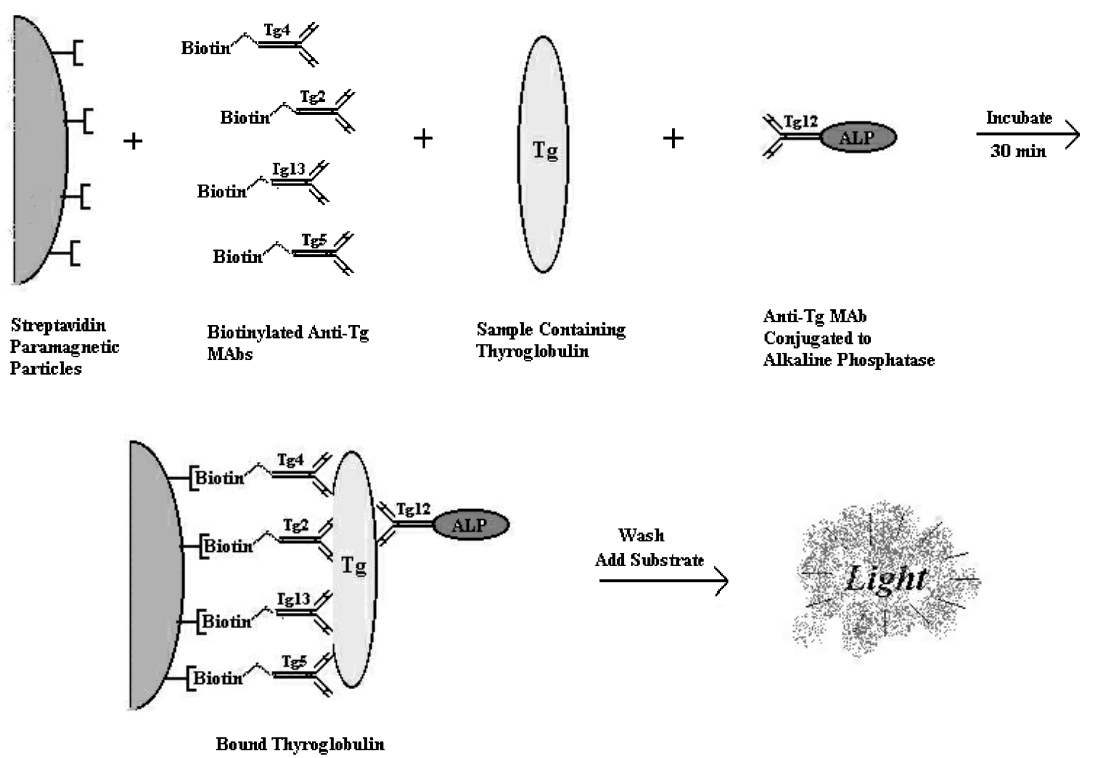

Figure 1 Schematic description of the Tg Access immunoassay: a simultaneous one-step immunoenzymatic (sandwich) assay. When the substrate, Lumi-Phos 530 (Lumigen Inc., Southfield, MI, USA), is added the reaction generates light which is measured with a luminometer and is directly proportional to the concentration of $\mathrm{Tg}$ in the sample. MAb, monoclonal antibodies; ALP, alkaline phosphatase.

(Spencer et al. 1996, 1997, Clark \& Beckett 2002, Demers $\&$ Spencer 2002). In the last 30 years, the analytical sensitivity of $\mathrm{Tg}$ measurement has been greatly improved, being about $5 \mu \mathrm{g} / 1$ with the first traditional radioimmunoassays (Van Herle et al. 1973) and 0.01-0.02 $\mu \mathrm{g} / 1$ with the recently developed immunoassay based on enzyme (Wunderlich et al. 2001, Zophel et al. 2003) or chemiluminescent tracer (Pressner et al. 2003). Thus, some methods can now achieve very good analytical and functional sensitivity giving reliable results in the very low concentration range. In addition, with the advent of fully automatized assays, such as the technique recently developed by Beckman Coulter on the Access analyzer, results are readily available to the clinician in less than $1 \mathrm{~h}$ while patients are still in the hospital.

In the present study, the analytical and clinical performance of the Tg Beckman Coulter assay on the Access analyzer were evaluated and compared with other known and substantially used immunoassays.

\section{Materials and Methods}

\section{Assay method}

The $\operatorname{Tg}$ Access immunoassay (Tg Access) (Beckman Coulter, Brea, CA, USA) is a chemiluminescent fully automated technique where samples can be processed at any time in a 'random access' format. The serum sample reacts with a biotinylated mixture of four monoclonal anti-Tg antibodies, streptavidin-coated paramagnetic particles and monoclonal anti-Tg antibody conjugated with alkaline phosphatase. The biotinylated antibodies and $\mathrm{Tg}$ in the serum bind to the solid phase, while the conjugated antibody reacts with a different antigenic site on the $\mathrm{Tg}$ molecule. After incubation and washing to remove material not bound to the solid phase, immobilized $\mathrm{Tg}$ is detected by the addition of a chemiluminescent enzyme substrate (see Fig. 1). The light generated is measured as relative light units (RLU) with a luminometer. Tg concentration is determined by a stored multipoint response curve calibrated to CRM 457 international reference preparation using a smoothing spline mathematic model (Feldt-Rasmussen \& Schlumberger 1988). The time to the first result is about $40 \mathrm{~min}$; sustained throughput is 100 tests/h.

The assay system was calibrated according to the manufacturer's instructions every 56 days throughout the course of the study. The calibration curve ranged from 0 to $480 \mu \mathrm{g} / \mathrm{l}$; in the range $0-1 \mu \mathrm{g} / \mathrm{l}$, the analytical response (RLU) showed a good improvement from approximately $9000 \mathrm{RLU}$ (standard at $0 \mu \mathrm{g} / \mathrm{l}$ ) to approximately 45000 RLU (standard at $0.93 \mu \mathrm{g} / 1$ ), namely a ratio of 5, as reported in Fig. 2, thus indicating that the assay achieves good precision in the low concentration range.

In this study, patients with positive $\mathrm{AbTg}$, measured using a two-step immunoenzymometric assay commercial kit performed on an AIA-21 analyser (Tosoh Bioscience, Tokyo, Japan), were excluded to rule out possible interference in the $\mathrm{Tg}$ assay; the minimal detectable 


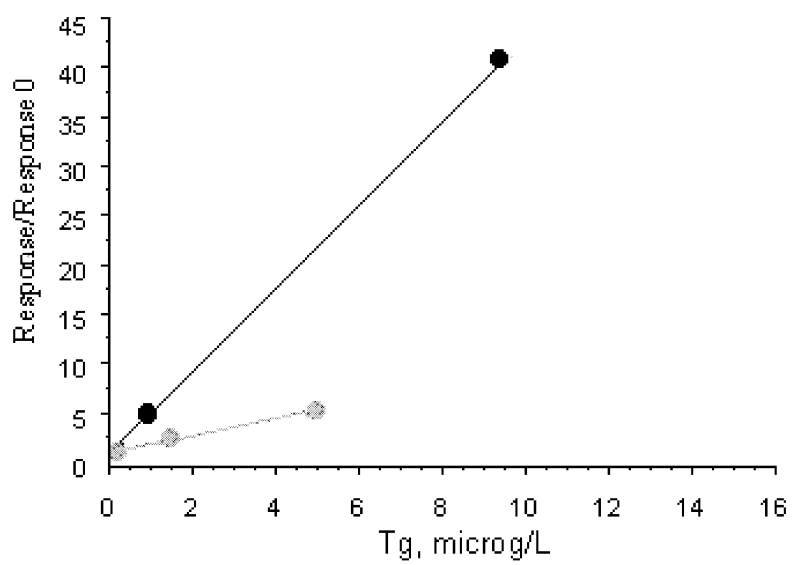

$\rightarrow$ Tg Access

* TgPasteur

Figure 2 Representation of the first part of the calibration curves (first three points) of the Tg Access and Tg Pasteur assays. To compare the calibration curves of the two methods the ratio of the response/response at $0 \mu \mathrm{g} / \mathrm{l}$ is shown on the ordinate.

concentration of $\mathrm{AbTg}$ was estimated to be $12 \mathrm{IU} / \mathrm{ml}$, samples with $\mathrm{AbTg}<12 \mathrm{IU} / \mathrm{ml}$ were considered negative.

\section{Analytical performance}

Detection limit The minimum detectable concentration (namely the detection limit or the analytical sensitivity), defined as the $\mathrm{Tg}$ value corresponding to a signal 3 S.D. above the mean of 20 replicates of the zero calibrator $(0 \mu \mathrm{g} / 1 \mathrm{Tg} ;$ Beckman $)$ and of a Tg-free serum from thyroidectomized patients, was determined.

Imprecision profile Ten serum pools, with different $\mathrm{Tg}$ concentration values, were prepared and stored at $-20^{\circ} \mathrm{C}$ until assayed. Each pool was periodically assayed from October 2003 to May 2004 (6 months) according to the National Academy of Clinical Biochemistry (NACB) guidelines to estimate the functional sensitivity (Demers \& Spencer 2002); different calibrations and different reagent lots were included and the imprecision profile (betweenassay imprecision) was calculated. Functional sensitivity was determined by interpolating the imprecision profile of $\mathrm{Tg}$ concentration assayed with a coefficient of variation (C.V.) of $20 \%$.

Within-assay imprecision Four serum samples were assayed in five replicates in the same run and the relative C.V. values were calculated (within-assay imprecision).

AbTg inteference Five serum samples from subjects without $\mathrm{AbTg}$ and containing a measurable concentration of Tg (range from 3.10 to $12.6 \mu \mathrm{g} / \mathrm{l}$, mean $6.98 \mu \mathrm{g} / \mathrm{l}$ ) were diluted with serum from a thyroidectomized and radioiodine-ablated patient (as a treatment for papillary carcinoma, stage I) who had been disease free for more than 10 years, affected by Hashimoto's thyroiditis, with Tg Access $<0.01 \mu \mathrm{g} / \mathrm{l}$, but with slightly positive AbTg values (about $150 \mathrm{IU} / \mathrm{ml}$ ); another five samples without $\mathrm{AbTg}$ and containing a measurable concentration of $\mathrm{Tg}$ (range from 3.94 to $23.8 \mu \mathrm{g} / \mathrm{l}$, mean $12.3 \mu \mathrm{g} / \mathrm{l}$ ) were diluted with a serum pool containing AbTg (about $300 \mathrm{IU} / \mathrm{ml}$ ) and $\mathrm{Tg}<1 \mu \mathrm{g} / \mathrm{l}$. The ten diluted sera, with a final $\mathrm{AbTg}$ concentration of $110 \mathrm{IU} / \mathrm{ml}$ (first group) and $220 \mathrm{IU} / \mathrm{ml}$ (second group), were assayed to check for interference by AbTg in the Tg Access assay.

Dilution test The reliability of $\mathrm{Tg}$ measurements in the low concentration range $(<1 \mu \mathrm{g} / \mathrm{l})$ was tested by progressively diluting a sample pool at $5 \cdot 27 \mu \mathrm{g} / 1$ with Tg-free serum obtained from thyroidectomized and radioiodine-ablated DTC, stage 1 , disease-free patients.

Normal range $\mathrm{Tg}$ concentrations were measured in the sera of 120 healthy AbTg-negative euthyroid individuals (mean age $22 \pm 8$ years, 69 males and 51 females; TSH range 0.4-3.9 $\mu \mathrm{U} / \mathrm{ml}$, mean $1.67 \mu \mathrm{U} / \mathrm{m}$; free T3 range $2 \cdot 1-3 \cdot 2 \mathrm{pg} / \mathrm{ml}$, mean $2 \cdot 35 \mathrm{pg} / \mathrm{ml}$; free T4 range $7 \cdot 1-18 \cdot 0 \mathrm{pg} / \mathrm{ml}$, mean $12 \cdot 0 \mathrm{pg} / \mathrm{ml}$ ), without a personal or family history of thyroid disease and with a normal thyroid pattern at ultrasonographic examination.

Heterophile antibody interference Interference by heterophile antibodies was checked by using heterophileblocking tubes (HTB; Scantibodies, Santee, CA, USA) according to the procedure suggested recently (Pressner et al. 2003) and Tg measurements were repeated after incubating $500 \mu \mathrm{l}$ of each serum at room temperature for $1 \mathrm{~h}$.

Method comparison $\mathrm{Tg}$ Access measurements were compared with a traditional widely used immunoradiometric assay (IRMA) produced by Pasteur (Gif-SurYvette Cedex, France) based on a mixture of four monoclonal anti-Tg antibodies such as were used in the $\mathrm{Tg}$ Access assay.

\section{Clinical performance}

To estimate the upper reference limit (cut-off) for DTC recurrence, 53 patients (47 women and six men aged $53 \pm 14$ years (means \pm S.D. )) were enrolled in the study. All of these patients had undergone total thyroidectomy and radioiodine ablation for primary treatment of stage I DTC, they had been 'disease-free' for more than 10 years and underwent routine follow-up at the time of the study. 
Stimulation with recombinant human TSH (rhTSH) was performed for routine follow-up in 22 consecutive unselected treated patients with DTC, and Tg was measured in basal conditions during suppressive therapy and 5 days after rhTSH.

This study was approved by our Institutional Ethics review Committee. Informed consent was obtained from all patients.

\section{Statistical analysis}

Continuous variables are expressed as means \pm S.D., a $P$ value less than $0 \cdot 05$ was considered statistically significant.

Deming regression was used to calculate analytical correlation between different methods; agreement between methods was assessed by the Bland and Altman plot (Cornbleet \& Gochman 1979, Bland \& Altman 1986, 1999).

\section{Results}

\section{Analytical performance}

Detection limit The detection limit was found to be $0 \cdot 007 \mu \mathrm{g} / \mathrm{l}$ using the zero standard $(0 \mu \mathrm{g} / \mathrm{l} \mathrm{Tg}$; Beckman) and $0.012 \mu \mathrm{g} / \mathrm{l}$ using $\mathrm{Tg}$-free serum and therefore a detection limit of $0 \cdot 01 \mu \mathrm{g} / 1$ was assumed. For comparison, the detection limit calculated for the Pasteur IRMA using $\mathrm{Tg}$-free serum was $0.54 \mu \mathrm{g} / 1$ (declared $0 \cdot 2 \mu \mathrm{g} / \mathrm{l})$.

Imprecision profile The imprecision profile (C.V. values) performed using ten different serum pools was as follows: $26 \cdot 8 \%$ at $0 \cdot 061 \mu \mathrm{g} / 1,14 \cdot 4 \%$ at $0 \cdot 14 \mu \mathrm{g} / 1,13 \cdot 8 \%$ at $0.31 \mu \mathrm{g} / 1,11 \cdot 3 \%$ at $0.65 \mu \mathrm{g} / 1,9.6 \%$ at $0.93 \mu \mathrm{g} / 1,7 \cdot 6 \%$ at $3 \cdot 1 \mu \mathrm{g} / 1,6 \cdot 7 \%$ at $9 \cdot 6 \mu \mathrm{g} / 1,4 \cdot 3 \%$ at $36 \cdot 2 \mu \mathrm{g} / 1,4 \cdot 3 \%$ at $64 \cdot 8 \mu \mathrm{g} / 1,4 \cdot 3 \%$ at $168 \mu \mathrm{g} / \mathrm{l}$; functional sensitivity was $0 \cdot 1 \mu \mathrm{g} / 1$ at $20 \%$ C.V.

Within-assay imprecision The C.V. values were $2 \cdot 7 \%$ at $0.18 \mu \mathrm{g} / 1,1.3 \%$ at $0.37 \mu \mathrm{g} / 1,1.5 \%$ at $0.56 \mu \mathrm{g} / 1$ and $2.0 \%$ at $0.75 \mu \mathrm{g} / 1$.

AbTg interference Mean recovery, estimated after adding sera containing $\mathrm{AbTg}$ to sera with $\mathrm{Tg}$, was $63 \cdot 8 \pm 16 \%$ (observed values versus expected values), thus indicating that the Tg Access assay, like other methods, was affected by interference from AbTg (Erali et al. 1996).

Dilution test $\mathrm{Tg}$ concentrations measured in samples progressively diluted with $\mathrm{Tg}$-free serum were found to be very close to the expected values (recovery 100-133\%) in the low concentration range and showed very good linearity (Fig. 3). The dilution test was also performed with the Tg Pasteur assay where only the first five diluted samples showed values above its detection limit $(0 \cdot 2 \mu \mathrm{g} / \mathrm{l})$ and the bias between observed and expected values was very high.
Normal range In normal subjects, $\mathrm{Tg}$ ranged from 2.55 to $64.3 \mu \mathrm{g} / 1$, with a median of $11.16 \mu \mathrm{g} / 1$ and a 95 th percentile concentration of $46.9 \mu \mathrm{g} / \mathrm{l}$. This result is in agreement with the suggested reference interval (NACB guidelines approximately 3-40 $\mathrm{g} / \mathrm{l}$; Demers \& Spencer 2002).

\section{Method comparison}

Comparison between the Access assay and the Pasteur IRMA was carried out on 64 samples and Deming regression analysis gave: $\mathrm{Tg}$ Access $=-1 \cdot 1+0.61 \mathrm{Tg}$ Pasteur, $r=0.99, P<0.001$ (Fig. 4).

\section{Clinical performance}

The cut-off at the 99th percentile of 53 long-term 'disease-free' patients previously treated for stage I DTC during suppressive L-T4 therapy was $0.16 \mu \mathrm{g} / \mathrm{l}$; five patients had $\mathrm{Tg}$ values below the assay detection limit $(<0 \cdot 01 \mu \mathrm{g} / \mathrm{l})$, whereas 48 patients showed a measurable $\mathrm{Tg}$ concentration up to $0 \cdot 19 \mu \mathrm{g} / 1$ (Fig. 5).

$\mathrm{Tg}$ measurements before (i.e. during suppressive therapy) and after (5 days) of rhTSH stimulation was performed in 22 sera obtaining different patterns of response. The main clinical and serological data are reported in Table 1. In 68\% of patients (15/22), basal Tg values were $<0 \cdot 1 \mu \mathrm{g} / \mathrm{l}$ : in $80 \%$ of these patients $(12 / 15) \mathrm{Tg}$ remained $<0 \cdot 1 \mu \mathrm{g} / 1$ also after rhTSH stimulation and only $1 / 12$ had a positive whole body scan (WBS), while in 20\% (3/15) Tg levels showed an increment but were always $<1 \mu \mathrm{g} / 1$ with $1 / 3$ having a positive WBS. In the other $32 \%$ of patients $(7 / 22), \mathrm{Tg}$ levels were $>0 \cdot 1 \mu \mathrm{g} / 1$ also in basal conditions; after rhTSH stimulation $\mathrm{Tg}$ was always detectable but there were two different patterns of response: $57 \%$ showed an increment of $\mathrm{Tg}$ values (4/7), with a positive WBS in $1 / 4$, while $43 \%$ showed a suspicious lack of response (3/7).

Interference by heterophile antibodies was tested in patients 77/F, 57/F and 46/M shown in Table 1. These three patients had detectable basal $\mathrm{Tg}(0.22,0.79$ and $2.77 \mu \mathrm{g} / 1$ respectively) but showed a lack of $\mathrm{rhTSH}-$ stimulated response $(0.20,0.66$ and $2.61 \mu \mathrm{g} / 1$ respectively). In patient $77 / \mathrm{F}, \mathrm{Tg}$ levels were also confirmed after the incubation of sera in HBT tubes (basal Tg $0.21 \mu \mathrm{g} / 1$ and after rhTSH $0 \cdot 28 \mu \mathrm{g} / \mathrm{l})$. In the other two patients, $\mathrm{Tg}$ levels dropped to $0.01 \mu \mathrm{g} / 1$ after incubation in HBT tubes, thus indicating a substantial interference by heterophile antibodies in the Tg Access assay. For comparison, further experiments in three unselected sera ( $\mathrm{Tg}$ concentration of $0 \cdot 71,4 \cdot 12$ and $10 \cdot 7 \mu \mathrm{g} / \mathrm{l})$ did not show any interference after incubation in HBT tubes (Tg values of $0 \cdot 59,4 \cdot 14$ and $11.9 \mu \mathrm{g} / 1$ respectively).

\section{Discussion}

Tg measurement is considered the best biochemical marker worldwide for detecting persistent or recurrent 


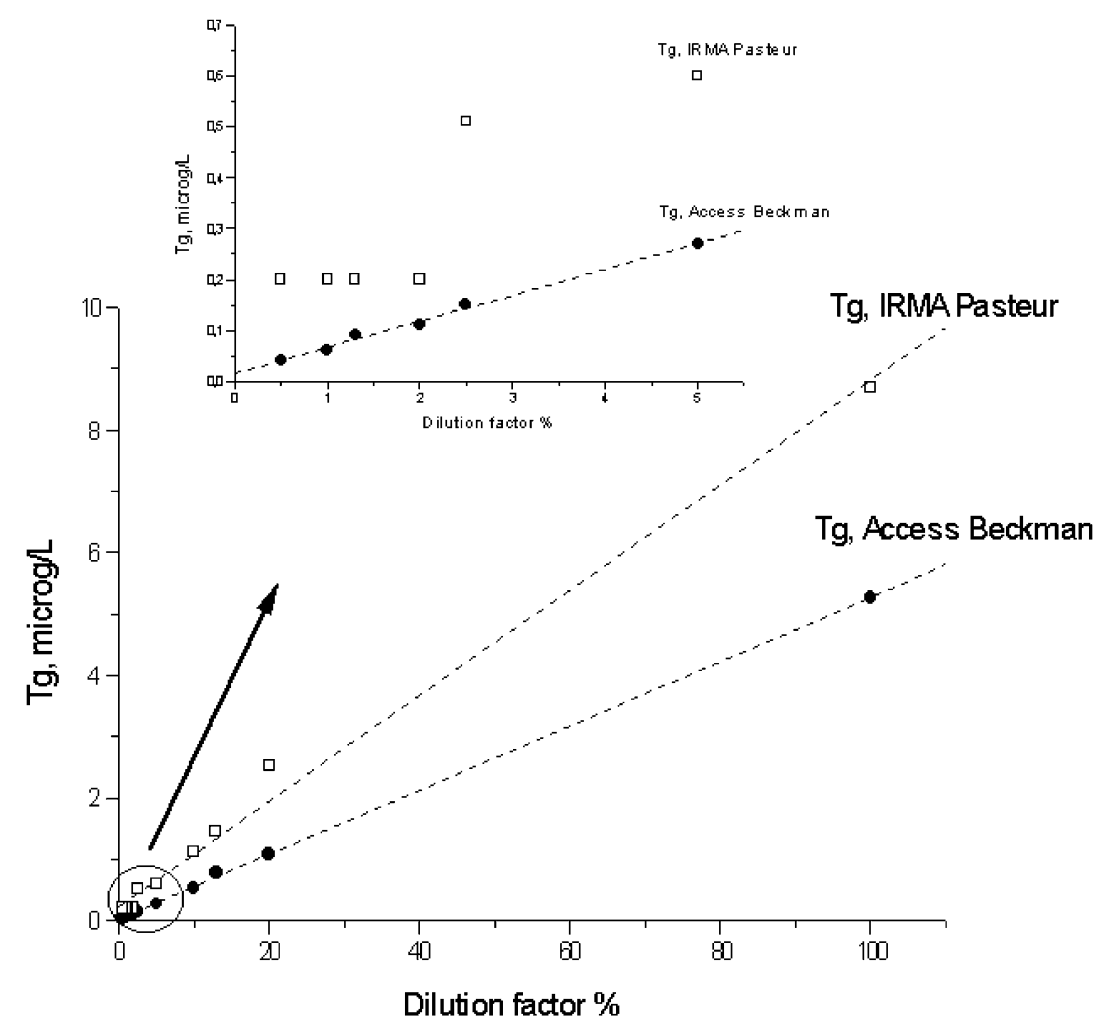

Figure 3 Dilution test for Tg Access ( $)$ and Tg Pasteur $(\square)$ performed by progressively diluting the same sample pool at $5 \cdot 27 \mu \mathrm{g} / \mathrm{l}$ (Access) and $8.69 \mu \mathrm{g} / \mathrm{l}$ (Pasteur) with Tg-free AbTg-free serum obtained from thyroidectomized and radio-ablated patients for DTC stage 1 treatment (see Materials and Methods). The dashed lines indicate linear regression.

diseases in the follow-up of patients affected by DTC (Kendall-Taylor 2003); the fundamental role of this assay is indirectly reinforced by the data from several recent

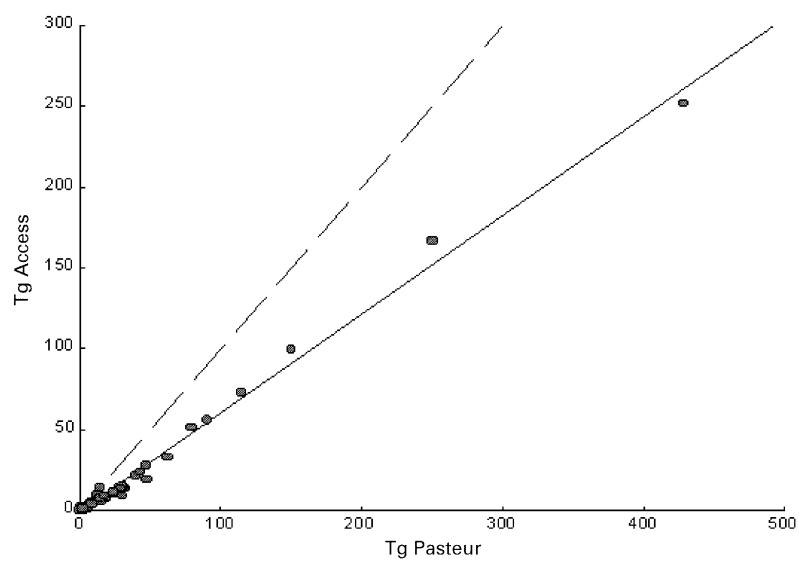

Figure 4 Deming regression between Tg Access and Pasteur. Solid line, regression; dashed line, identity. (Directly represented by the freeware software Method Validator by Philippe Marquis). Unweighted Deming regression, $n=64$. Slope, $0 \cdot 612$ (0.532-0.692). Intercept, $-1.085(-2 \cdot 601-0 \cdot 432)$.

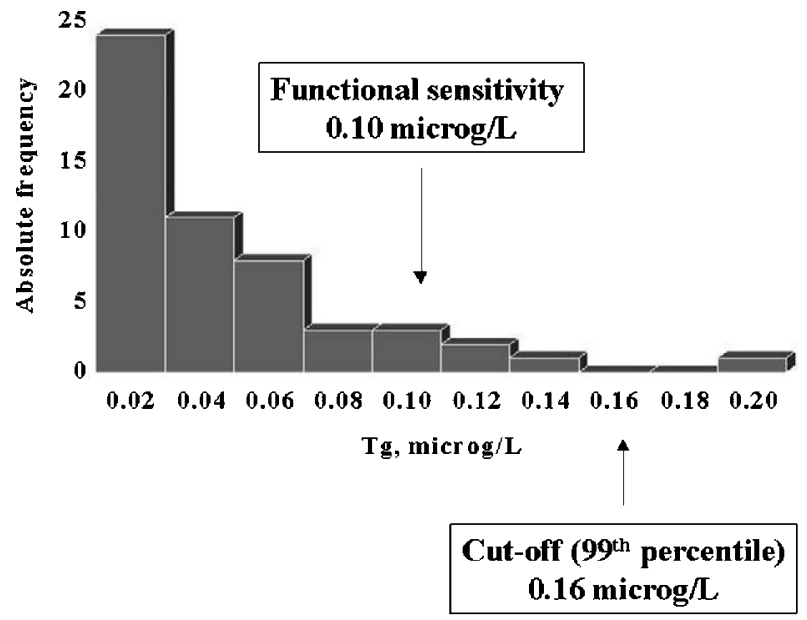

Figure 5 Distribution of 53 patients who had undergone total thyroidectomy and radioiodine ablation for primary treatment of stage I DTC and who had been disease free for more than 10 years; five patients had $\mathrm{Tg}$ values below the assay detection limit $(0.01 \mu \mathrm{g} / \mathrm{l})$ whereas 48 patients showed a Tg concentration up to $0 \cdot 19 \mu \mathrm{g} / \mathrm{l}$. Functional sensitivity and cut-off at the 99th percentile are indicated. 
Table 1 Main clinical data and Tg measurements before and after 5 days of rhTSH in patients with DTC

\begin{tabular}{|c|c|c|c|c|c|c|c|c|c|}
\hline & $\begin{array}{l}\text { First } \\
\text { diagnosis } \\
\text { and treatment }\end{array}$ & TNM UICC '02* & Histology† & $\begin{array}{l}\text { Tg Access } \\
\text { basalł } \\
(\mu \mathrm{g} / \mathrm{l})\end{array}$ & $\begin{array}{l}\text { Tg Access } \\
\text { after rhTSH‡ } \\
(\mu \mathrm{g} / \mathrm{l})\end{array}$ & $\begin{array}{l}\text { US } \\
\text { TB } \|\end{array}$ & $\begin{array}{l}\text { US } \\
\text { ex TB } \|\end{array}$ & $\begin{array}{l}\text { WBS } \\
\text { TB§ }\end{array}$ & $\begin{array}{l}\text { WBS } \\
\text { ex TB§ }\end{array}$ \\
\hline \multicolumn{10}{|c|}{$\begin{array}{l}\text { Patients } \\
\text { (age/sex) }\end{array}$} \\
\hline $46 / F$ & 1998 & $\mathrm{~T} 1, \mathrm{~N} 0, \mathrm{MO}$ & Pap & $<0 \cdot 01(<0 \cdot 2)$ & $<0 \cdot 01(<0 \cdot 2)$ & Neg & Neg & Pos & Neg \\
\hline $39 / F$ & 1998 & $\mathrm{~T} 3, \mathrm{~N} 1, \mathrm{Mx}-\mathrm{S} 1$ & Pap & $<0 \cdot 01(<0 \cdot 2)$ & $0 \cdot 01(<0 \cdot 2)$ & Neg & Neg & Neg & Neg \\
\hline $51 / \mathrm{F}$ & 1993 & T1, No-S1 & Pap & $<0.01(0 \cdot 2)$ & $<0.01(0 \cdot 2)$ & Neg & Neg & Neg & Neg \\
\hline $45 / F$ & 1997 & $\mathrm{~T} 1, \mathrm{~N} 0, \mathrm{Mx}-\mathrm{S} 1$ & Pap & $0 \cdot 04(<0 \cdot 2)$ & $0 \cdot 01(<0 \cdot 2)$ & Neg & Neg & $\mathrm{Neg}$ & Neg \\
\hline $49 / M$ & 2000 & $\mathrm{~T} 1, \mathrm{~N} 0, \mathrm{Mx}-\mathrm{S} 1$ & Pap & $0 \cdot 04(<0 \cdot 2)$ & $0 \cdot 06(<0 \cdot 2)$ & Neg & Neg & Neg & Neg \\
\hline $70 / F$ & 1995 & T1, NO-S1 & Pap & $0 \cdot 04(<0 \cdot 2)$ & $0 \cdot 05(<0 \cdot 2)$ & Neg & Neg & Neg & Neg \\
\hline $73 / F$ & 1991 & $\mathrm{~T} 1, \mathrm{~N} 0, \mathrm{MO}$ & Pap & $0 \cdot 04(<0 \cdot 2)$ & $0 \cdot 05(<0 \cdot 2)$ & Neg & Neg & Neg & Neg \\
\hline $30 / F$ & 1996 & T4a, N1a, Mx-S1 & Pap & $0 \cdot 04(<0 \cdot 2)$ & $0.09(<0 \cdot 2)$ & Neg & Neg & Neg & Neg \\
\hline $50 / \mathrm{M}$ & 2001 & $\mathrm{~T} 2, \mathrm{~N} 0, \mathrm{MO}$ & Pap, var foll & $0 \cdot 04(<0 \cdot 2)$ & $0 \cdot 05(<0 \cdot 2)$ & Neg & Neg & Neg & $\mathrm{Fp}$ \\
\hline $77 / F$ & 2001 & $\mathrm{~T} 1, \mathrm{Nx}, \mathrm{Mx}-\mathrm{S} 1$ & Pap & $0 \cdot 22(<0 \cdot 2)$ & $0 \cdot 02(0 \cdot 2)$ & Neg & Neg & Neg & Neg \\
\hline $60 / F$ & 2000 & T1, N1a, Mx-SIII & Pap & $0 \cdot 28(<0 \cdot 2)$ & $2 \cdot 27(0 \cdot 8)$ & Neg & Neg & Neg & Neg \\
\hline $53 / \mathrm{F}$ & 1995 & $\mathrm{~T} 1, \mathrm{~N} 0, \mathrm{MO}$ & Pap & $0 \cdot 31(0 \cdot 3)$ & $0.57(0.6)$ & Neg & Neg & Pos & Neg \\
\hline $50 / F$ & 1998 & $\mathrm{~T} 1, \mathrm{~N} 0, \mathrm{MO}$ & Pap & $0 \cdot 47(<0 \cdot 2)$ & $0 \cdot 81(0.5)$ & Neg & Neg & Neg & Neg \\
\hline $57 / F$ & 1994 & $\mathrm{~T} 2 \mathrm{~m}, \mathrm{~N} 0, \mathrm{MO}-\mathrm{S} 1$ & Pap & $0.79(<0 \cdot 2)$ & $0 \cdot 66(<0 \cdot 2)$ & Neg & Neg & Neg & Neg \\
\hline $46 / M$ & 2001 & $\mathrm{~T} 2, \mathrm{Nx}, \mathrm{Mx}-\mathrm{S} 1$ & Pap, var foll & $2 \cdot 77(0 \cdot 3)$ & $2 \cdot 61(<0 \cdot 2)$ & Neg & Neg & Neg & $\mathrm{Neg}$ \\
\hline $61 / F$ & 1997 & T2, N1, Mx-SIII & Ins & $99 \cdot 2(66 \cdot 8)$ & $334 \cdot 8(222 \cdot 8)$ & Neg & Pos & Neg & Neg \\
\hline
\end{tabular}

*TNM UICC '02: tumour classification according to the International Union Against Cancer.

†Histology: Pap, papillary; var foll, variant follicular; Ins, poorly differentiated 'insular' follicular carcinoma; hc, papillary variant high cells. $\ddagger$ Tg values measured by Pasteur IRMA are shown in parentheses.

II US TB: negative (Neg) or positive (Pos) ultrasonography for thyroid remnants in the thyroid bed; US ex TB, for cervical lymph nodes. §WBS TB: Neg or Pos pathological ${ }^{13}$ I uptake in the thyroid bed; WBS ex TB, in the extra-thyroid bed (Fp, false positive).

studies (Hardy et al. 1995, Schlumberger \& Baudin 1998, Teppo \& Hakulinen 1998, Vanderpump et al. 1998, Spencer et al. 1999, Kumar et al. 2001, Torens \& Burch 2001).

Theoretically, an ideal biomarker should be highly sensitive and specific and should be able to be reproduced across different clinical laboratories. The inherent error in the measurement itself (C.V.) should be sufficiently low that small changes in the level of the biomarker reflect true changes in the clinical status of the patient. Finally, the assay should be relatively easy to perform and analyze so that the information is readily available to the clinician.

Tg assay performed with the Access analyzer as evaluated in our laboratory appears to satisfy most of these characteristics, providing analytical and clinical performance comparable with the most commonly used methods. This method permits a lower detection limit $(0 \cdot 01 \mu \mathrm{g} / \mathrm{l})$, a lower functional sensitivity $(0 \cdot 1 \mu \mathrm{g} / \mathrm{l})$ and a lower cut-off for patients with DTC $(0 \cdot 16 \mu \mathrm{g} / \mathrm{l})$; the latter, in particular, was sixfold lower than that reported in the latest guidelines (Mazzaferri 1999, Mazzaferri et al. 2003). These results are even better than those found recently (Giovanella \& Ceriani 2002). In addition, Tg Access is fast (40 min), feasible, simple, technically undemanding and potentially accessible to all medical centres contrary to the previous radioactive (IRMA) methods. The clinical importance of a reliable and accurate $\mathrm{Tg}$ determination is even more emphasized by the recent use of $\mathrm{Tg}$ measurements after rhTSH stimulation. Actually, serum Tg measured during TSH stimulation (endogenous TSH or rhTSH) is more sensitive than the basal Tg value obtained during L-T4 treatment (Haugen et al. 1999); using this approach the presence of cancer is identified before diagnostic ${ }^{131} \mathrm{I}$ WBS can localize the tumour (Cailleux et al. 2000, Mazzaferri \& Kloos 2000, 2002, Pacini et al. 2001, 2002, Haugen et al. 2002, Pellegriti et al. 2003). Interesting clinical conclusions can be drawn from the results of our pilot study on the use of $\mathrm{Tg}$ Access measurements during suppressive therapy and after rhTSH stimulation. In all patients with $\mathrm{Tg}<0 \cdot 1 \mu \mathrm{g} / 1$ during suppressive $\mathrm{L}-\mathrm{T} 4$ therapy, $\mathrm{Tg}$ after rhTSH remained $<1 \mu \mathrm{g} / 1$ or, in $80 \%$ of these patients, $\mathrm{Tg}$ levels remained $<0 \cdot 1 \mu \mathrm{g} / 1$ after the $\mathrm{rhTSH}$. These data indicated that the $\mathrm{Tg}$ Access assay could also be useful in the very low concentration range $(<0 \cdot 1 \mu \mathrm{g} / \mathrm{l})$ during suppressive L-T4 treatment, being able to discriminate low-risk patients. These preliminary findings show the high sensitivity of $\mathrm{Tg}$ measurements in the follow-up of low-risk patients with DTC, not only after rhTSH 
stimulation but also during suppressive therapy. The $\mathrm{Tg}$ Access assay therefore seems to give very good clinical sensitivity (no false-negative patients) and specificity (no false-positive patients). This could be useful for choosing better and less aggressive protocols. At the moment, the commercially used $\mathrm{Tg}$ assays are not able to discriminate small differences in the low concentration range, Tg results below $1 \mu \mathrm{g} / 1$ are considered to be in the 'grey' zone. Tg Access measurement could then be useful in the clinical assessment of patients to be submitted to ${ }^{131} \mathrm{I}$ WBS; in fact the usefulness of WBS after rhTSH when $\mathrm{Tg}$ values remain below $1 \mu \mathrm{g} / \mathrm{l}$, now considered to be the gold standard for sensitivity (Torlontano et al. 2003, Koh et al. 2003), is still controversial.

Our results on $\mathrm{AbTg}$ interference, even though obtained in a limited number of patients, demonstrated that $\mathrm{Tg}$ determination was affected by the presence of AbTg using the Tg Access method. For this reason, in all samples where $\mathrm{Tg}$ concentration was measured in our laboratory, we also measured $\mathrm{AbTg}$ concentrations and when $\mathrm{AbTg}$ was positive we considered the $\mathrm{Tg}$ value to be not reliable. Besides the interference by $\mathrm{AbTg}$ which produced false-negative results, the assay was also interfered with by heterophile antibodies which produced false-positive results, in agreement with a previous report on Tg Access assay performance (Pressner et al. 2003). However, we wish to point out that the problem of antibody interference in Tg measurement is still a problem which affects any commercially available method (Demers \& Spencer 2002).

In conclusion, Access Tg measurement could represent an improvement in terms of analytical sensitivity and precision when compared with the most widely employed assays. Moreover, the very good practicality of this test makes its routine application even easier. Further retrospective and prospective studies in a large series of patients treated for DTC will indicate its real usefulness in clinical practice.

\section{Acknowledgements}

We would like to thank Mrs Laura Mazza for her skilful secretarial assistance.

\section{References}

Bland JM \& Altman DG 1986 Statistical methods for assessing agreement between two methods of clinical measurement. Lancet 8 307-310.

Bland JM \& Altman DG 1999 Measuring agreement in method comparison studies. Statistical Methods in Medical Research 8 135-160.

Cailleux AF, Baudin E, Travagli JP, Ricard M \& Schlumberger M 2000 Is diagnostic iodine-131 scanning useful after total thyroid ablation for differentiated thyroid cancer? Journal of Clinical Endocrinology and Metabolism 85 175-178.
Clark PM \& Beckett G 2002 Can we measure serum thyroglobulin? Annals of Clinical Biochemistry 39 196-202.

Cornbleet PJ \& Gochman N 1979 Incorrect least-squares regression coefficients in method-comparison analysis. Clinical Chemistry 25 432-438.

Demers LM \& Spencer CA (eds) National Academy of Clinical Biochemistry 2002 Laboratory support for the diagnosis and monitoring of thyroid disease. Available at http://www.nacb.org/lmpg/thyroid_lmpg_pub.stm.

Duren M, Siperstein AE, Shen W, Duh Q-Y, Morita E \& Clark OH 1999 Value of stimulated serum thyroglobulin levels for detecting persistent or recurrent differentiated thyroid cancer in high- and low-risk patients. Surgery 126 13-19.

Erali M, Bigelow RB \& Meikle AW 1996 Elisa for thyroglobulin in serum: recovery studies to evaluate autoantibodies interference and reliability of thyroglobulin values. Clinical Chemistry 42 766-770.

Feldt-Rasmussen U \& Schlumberger M 1988 European interlaboratory comparison of serum thyroglobulin measurement. Journal of Endocrinological Investigation 11 175-181.

Giovanella L \& Ceriani L 2002 High-sensitivity human thyroglobulin (hTg) immunoradiometricassay in the follow-up of patients with differentiated thyroid cancer. Clinical Chemistry and Laboratory Medicine 40 480-484.

Girelli ME \& De Vido D 2000 Serum thyroglobulin measurement in differentiated thyroid cancer. Biomedical Pharmacotherapy $\mathbf{5 4}$ 330-333.

Hardy KJ, Walker BR, Lindsay RS, Kennedy RL, Seckl JR \& Padfield PL 1995 Thyroid cancer management. Clinical Endocrinology 42 651-655.

Haugen BR, Pacini F, Reiners C, Schlumberger M, Ladenson PW, Sherman SI, Cooper DS, Graham KE, Braverman LE, Skarulis MC et al. 1999 A comparison of recombinant human thyrotropin and thyroid hormone withdrawal for the detection of thyroid remnant or cancer. Journal of Clinical Endocrinology and Metabolism $\mathbf{8 4}$ 3877-3885.

Haugen BR, Ridgway ECMC, Laughlin BA \& McDermott MT 2002 Clinical comparison of whole-body radioiodine scan and serum thyroglobulin after stimulation with recombinant human thyrotropin. Thyroid 12 37-43.

Kendall-Taylor P on behalf of the Guidelines Working Group 2003 Guidelines for the management of thyroid cancer. Clinical Endocrinology 58 400-402.

Koh J-M, Kim ES, Ryu JS, Hong SJ, Kim WB \& Shong YK 2003 Effects of therapeutic dose of $131 \mathrm{I}$ in thyroid papillary carcinoma patients with elevated thyroglobulin level and negative $131 \mathrm{I}$ whole-body scan: comparative study. Clinical Endocrinology 158 421-425.

Kumar H, Daykin J, Holder R, Watkinson JC, Sheppard MC \& Franklin JA 2001 An audit of management of differentiated thyroid cancer in specialist and nonspecialist clinic setting. Clinical Endocrinology 54 719-723.

Mazzaferri EL 1999 NCCN thyroid carcinoma practice guidelines. Oncology 13 391-442.

Mazzaferri EL \& Kloos RT 2000 Using recombinant human TSH in the management of well-differentiated thyroid cancer: current strategies and future directions. Thyroid $10767-778$.

Mazzaferri EL \& Kloos RT 2002 Is diagnostic iodine-131 scanning with recombinant human TSH useful in the follow-up of differentiated thyroid cancer after thyroid ablation? Journal of Clinical Endocrinology and Metabolism 87 1490-1498.

Mazzaferri EL, Robbins RJ, Spencer CA, Braverman LE, Pacini F, Wartofsky L, Haugen BR Sherman SI, Cooper DS, Braunstein GD et al. 2003 A consensus report of the role of serum thyroglobulin as a monitoring method for low-risk patients with papillary thyroid carcinoma. Journal of Clinical Endocrinology and Metabolism $\mathbf{8 8}$ 1433-1441. 
Ozata M, Suzuki S, Miyamoto T, Liu RT, Fierro-Renoy F \& Degroot LJ 1994 Serum thyroglobulin in the follow-up of patients with treated differentiated thyroid cancer. Journal of Clinical Endocrinology and Metabolism 79 98-105.

Pacini F \& Pinchera A 1999 Serum and tissue thyroglobulin measurement: clinical application in thyroid disease. Biochimie $\mathbf{8 1}$ 463-467.

Pacini F, Molinaro E, Lippi F, Castagna MG, Agate L, Ceccarelli C, Taddei D, Elisei R, Capezzone M \& Pinchera A 2001 Prediction of disease status by recombinant human TSH- stimulated serum $\mathrm{Tg}$ in the post surgical follow-up of differentiated thyroid carcinoma. Journal of Clinical Endocrinology and Metabolism 86 5686-5690.

Pacini F, Capezzone M, Elisei R, Ceccarelli C, Taddei D \& Pinchera A 2002 Diagnostic 131-iodine whole body scan may be avoided in thyroid cancer patients who have undetectable stimulated serum $\mathrm{Tg}$ levels after initial treatment. Journal of Clinical Endocrinology and Metabolism 87 1499-1501.

Pellegriti G, Scollo C, Regalbuto C, Attard M, Marozzi P, Vermiglio F, Violi MA, Cianci M, Vigneri R, Pezzino V et al. 2003 The diagnostic use of rhTSH/thyroglobulin test in differentiated thyroid cancer patients with persistent disease and low thyroglobulin levels. Clinical Endocrinology 58 556-560.

Pressner CM, O’Kane DJ, Singh RJ, Morris JC \& Grebe SKG 2003 Phantoms in the assay tube: heterophile antibody interferences in serum thyroglobulin assays. Journal of Clinical Endocrinology and Metabolism 88 3069-3074.

Schlumberger M 1998 Papillary and follicular thyroid carcinoma. New England Journal of Medicine 338 297-306.

Schlumberger M \& Baudin E 1998 Serum thyroglobulin determination in the follow-up of patients with differentiated thyroid carcinoma. European Journal of Endocrinology 138 249-252.

Spencer CA, Takeuchi M \& Kazarosyan M 1996 Current status and performance goals for serum thyroglobulin assays, Clinical Chemistry 42 164-173.

Spencer CA, Takeuchi M, Kazarosyan M, Wang CC, Guttler RB, Singer PA, Fatemi S, LoPresti JS \& Nicoloff JT 1997 Serum thyroglobulin autoantibodies: prevalence, influence on serum thyroglobulin measurement, and prognostic significance in patients with differentiated thyroid carcinoma. Journal of Clinical Endocrinology and Metabolism 83 1121-1127.

Spencer CA, LoPresti JS, Fatemi S \& Nicoloff JT 1999 Detection of residual and recurrent differentiated thyroid carcinoma by serum thyroglobulin measurement. Thyroid 9 435-441.

Teppo L, Hakulinen T \& Eurocare Working Group 1998 Variation in survival of adult patients with thyroid cancer in Europe. European Journal of Cancer 34 2238-2252.

Torens JI \& Burch HB 2001 Serum thyroglobulin measurement. Utility in clinical practice. Endocrinology and Metabolism Clinics of North America 30 429-467.

Torlontano M, Crocetti U, D'Aloiso L, Bonfitto N, Di Giorgio A, Modoni S, Valle G, Frusciante V, Bisceglia M, Filetti S et al. 2003 Serum thyroglobulin and $131 \mathrm{I}$ whole body scan after recombinant human TSH stimulation in the follow-up of low-risk patients with differentiated thyroid cancer. European Journal of Endocrinology 148 19-24.

Vanderpump MPJ, Alexander L, Scarpello JHB \& Clayton RN 1998 An audit of management of thyroid cancer in a district general hospital. Clinical Endocrinology 48 419-424.

Van Herle AJ, Uller RP, Matthews NI \& Brown J 1973 Radioimmunoassay for measurement of thyroglobulin in human serum. Journal of Clinical Investigation 52 1320-1327.

Wunderlich G, Zophel K, Crook L, Smith S, Rees Smith B \& Franke WG 2001 A high-sensitivity enzyme-linked immunosorbent assay for serum thyroglobulin. Thyroid 11 819-824.

Zophel K, Wunderlich G \& Rees Smith B 2003 Serum thyroglobulin measurements with a high-sensitivity enzyme-linked immunosorbent assay: is there clinical benefit in patients with differentiated thyroid cancer? Thyroid 13 861-865.

Zucchelli GC, Pilo A, Masini S, Prontera C \& Ferdeghini M 1996 Large between-laboratoty variability of thyroglobulin immunoassays: data collected in a collaborative study. Journal of Clinical Ligand Assay 19 234-238.

Received in final form 17 May 2004

Accepted 18 May 2004 